\title{
High-definition-iSCAN virtual chromoendoscopy has high sensitivity and specificity for the diagnosis of eosinophilic esophagitis
}

\section{다(1)이우}

\author{
Authors \\ Eustace Gregory ${ }^{1}$, Miriam Fort Gasia ${ }^{1}$, Xianyong Gui ${ }^{3}$, Subrata Ghosh ${ }^{1,2}$, Marietta lacucci ${ }^{1,2}$
}

Institutions

1 Department of Medicine, Division of Gastroenterology, University of Calgary Cumming School of Medicine, Alberta, Canada

2 Institute of Translational of Medicine, University of Birmingham, UK

3 Department of Pathology, University of Calgary Cumming School of Medicine, Alberta, Canada

submitted 25.7.2016

accepted after revision 15.2.2017

\author{
Bibliography \\ DOI https://doi.org/10.1055/s-0043-111591 | \\ Endoscopy International Open 2017; 05: E613-E621 \\ (c) Georg Thieme Verlag KG Stuttgart · New York \\ ISSN 2364-3722
}

\section{Corresponding author}

Dr Marietta lacucci, MD, PhD, Clinical Associate Professor, Gastroenterology Division, University of Calgary, Teaching Research and Wellness Center, 3280 Hospital Drive NW, Calgary Alberta T2N4N1

Fax: 403-592-5090

miacucci@ucalgary.ca

\section{ABSTRACT}

Background and study aims A major challenge in eosinophilic esophagitis (EoE) is disease recognition during endoscopy as there are no pathognomonic findings. We aimed to determine the utility of high-definition (HD) iSCAN virtual chromoendoscopy (VC) in diagnosis of EoE.
Patients and methods One hundred eighty-nine consecutive patients presenting with dysphagia or food bolus impaction were assessed using HD-iSCAN VC (Pentax, Japan) with biopsies from distal, mid, upper esophagus and from furrows where visible.

Results Of 189 patients, 45 ( $23.8 \%$, male $=29$, median age $40 y$ ) had a histological diagnosis of EoE; $73.3 \%$ of the patients were newly diagnosed. iSCAN endoscopic features of EoE were linear furrows (91\%), edema (77.8\%), rings or tracheal appearance (73.3\%), whitish exudates (26.6\%) and narrowing or stricture (5\%). One patient $(2.2 \%)$ had all 5 endoscopic features. Ten patients $(22.2 \%$ ) had linear furrows, edema, rings or tracheal appearance and whitish exudates on iSCAN, with a positive predictive value (PPV) $100 \%$ (95\% Cl 69.1\%-100\%) and negative predictive value (NPV) $80.4 \%$ (95\% Cl $73.9 \%-86 \%$ ). Thirteen patients (29\%) presented with linear furrows, edema and rings or tracheal appearance on iSCAN, with a PPV $100 \%$ (95\% CI 75.3\%-100\%) and NPV $81.8 \%$ (95\% CI 75.3\%-87.2\%). Six patients (13.3\%) had furrows and edema and 6 patients (13.3\%) had furrows and rings or tracheal appearance on iSCAN, with a PPV $100 \%$ (95\% CI 54.1\%-100\%) and NPV 78.69\% (95\% CI 72\%-84.4\%), respectively. The sensitivity and specificity of HD-iSCAN endoscopy were $97.62 \%(95 \% \mathrm{Cl} 87.43 \%-99.94 \%)$ and $89.58 \%$ (95\% Cl 83.40\%-94.05\%). The accuracy of HD-iSCAN endoscopy was $92.47 \%$ (95\% Cl 87.67\%-95.56\%).

Conclusion HD-iSCAN endoscopy is sensitive and specific with good accuracy for EoE diagnosis. Linear furrows, edema and tracheal appearance were the most common findings and these 3 endoscopic features had a high predictive value for diagnosis of EoE.

\section{Introduction}

Eosinophilic esophagitis (EoE) is an inflammatory condition of the esophagus defined clinically by symptoms of esophageal dysfunction including dysphagia, reflux and food impaction [1-3] and histologically by an eosinophil predominant inflammatory response [4].
The first described case of the disorder was in pediatric literature by Landres et al. in 1978 [5]. It was not until 1993 that cases in adult literature were described. Since then, however, likely due to both increased recognition and increasing incidence [6], the number of cases has skyrocketed. Dellon et al. conducted a large study of over 35 million individuals in the United States with estimates of overall adult prevalence of EoE at 56.7/100000 [3]. Other smaller studies have reported adult 
- Table 1 Sensitivity, specificity, PPV and NPV of HD-iSCAN and EoE endoscopic findings.

\begin{tabular}{|c|c|c|c|c|}
\hline HD-iSCAN & $\begin{array}{l}\text { Sensitivity } \\
(95 \% \mathrm{Cl})\end{array}$ & $\begin{array}{l}\text { Specificity } \\
(95 \% \mathrm{Cl})\end{array}$ & $\begin{array}{l}\text { PPV } \\
\text { (95\%Cl) }\end{array}$ & $\begin{array}{l}\text { NPV } \\
(95 \% \mathrm{Cl})\end{array}$ \\
\hline Linear furrows & $\begin{array}{l}91.1 \% \\
(78.7-97.5)\end{array}$ & $\begin{array}{l}93.75 \\
(88.4-97.1)\end{array}$ & $\begin{array}{l}82 \% \\
(68.5-97.1)\end{array}$ & $\begin{array}{l}97.1 \% \\
(92.8 \%-99.2)\end{array}$ \\
\hline Edema & $\begin{array}{l}77.7 \% \\
(62.9-88.8)\end{array}$ & $\begin{array}{l}100 \% \\
(97.4-100)\end{array}$ & $\begin{array}{l}100 \% \\
(90-100)\end{array}$ & $\begin{array}{l}93.5 \% \\
(88.3-96.8)\end{array}$ \\
\hline Ring or tracheal appearance & $\begin{array}{l}73.3 \% \\
(58.06-85.4)\end{array}$ & $\begin{array}{l}93.06 \% \\
(87.6-96.6)\end{array}$ & $\begin{array}{l}76.7 \% \\
(61.3-88.2)\end{array}$ & $\begin{array}{l}91.7 \% \\
(86-95.6)\end{array}$ \\
\hline White exudate & $\begin{array}{l}26.6 \% \\
(14.6-41.9)\end{array}$ & $\begin{array}{l}97.9 \% \\
94.03-99.5)\end{array}$ & $\begin{array}{l}80 \% \\
(51.9-95.6)\end{array}$ & $\begin{array}{l}81 \% \\
(74.4-86.5)\end{array}$ \\
\hline Narrowing stricture & $\begin{array}{l}4.4 \% \\
(0.54-15.1)\end{array}$ & $\begin{array}{l}100 \% \\
(97.4-100)\end{array}$ & $\begin{array}{l}100 \% \\
(15.8-100)\end{array}$ & $\begin{array}{l}77 \% \\
(70.3-82.8 \%)\end{array}$ \\
\hline
\end{tabular}

- Table 2 Cause of dysphagia in our patient cohort.

\begin{tabular}{|l|l|}
\hline Cause of dysphagia & $\begin{array}{l}\text { Patients with dysphagia } \\
(\mathbf{n}=\mathbf{1 8 9}) \mathbf{( \% )}\end{array}$ \\
\hline GERD & $64(33.8)$ \\
\hline Rings and webs & $18(9.5)$ \\
\hline Eosinophilic esophagitis & $45(23.8)$ \\
\hline Unknown/functional & $34(18)$ \\
\hline Motility disorders & $9(4.8)$ \\
\hline Peptic stricture & $5(2.6)$ \\
\hline Extrinsic compression & $5(2.6)$ \\
\hline Malignancy & $4(2.1)$ \\
\hline Benign tumour & $2(1)$ \\
\hline Radiation esophagitis & $1(0.5)$ \\
\hline Others & \\
\hline - Esophageal varices & $1(0.5)$ \\
\hline - GvHD & $1(0.5)$ \\
\hline GERD, gastroephageal reflux disease; GrHD, graft versus host disease \\
\hline
\end{tabular}

prevalence of anywhere from 23/100000 in a Swiss study to $400 / 100000$ in a smaller study from Sweden [7,8]. It is now recognized as a relatively common clinically relevant and potentially manageable disorder.

While consensus guidelines exist on the histological diagnosis of EoE after biopsy, one of the major barriers remains recognition and subsequent biopsy sampling during endoscopy. Eosinophilic infiltrate is known to be patchy, which can increase sampling error [9]. Typical endoscopic findings have been reported with varying prevalence, including esophageal rings or trachealization, linear furrowing, white exudates, and edema $[4,10,11]$. Recent studies have suggested that targeted sampling within these findings may increase yield over conventional random biopsy sampling [12]. Endoscopic findings may be very subtle, however, and biopsies may never be taken. Two recent studies have suggested increasing diagnostic yield as well as recognition of novel features of EoE using optical enhancement endoscopy and biopsy such as Narrow Band Imaging (NBI) [13, 14]. Therefore, in our routine standard practice, we have adopted use of HD and virtual chromoendoscopy to better detect, characterize and enhance endoscopic findings of EoE and take additional biopsies from the furrows. We did not analyze biopsy sites.

We aimed to determine the utility of high-definition (HD) isCAN virtual chromoendoscopy in recognition and diagnosis of EoE.

\section{Patients and methods Study design}

This was a retrospective study performed at a single large tertiary care center, conducted over a period of 47 months from August 2011 to July 2015. The study was approved by the Calgary Conjoint Health Services Research Ethics Board of the University of Calgary

\section{Patients}

All patients presenting with either dysphagia or food bolus impaction under the care of a single gastroenterologist (M.I.) were included in the analysis. Based on these criteria, 189 consecutive patients (53.4\% male, median age 55 , age range $18-$ 85 years) were assessed by HD-iSCAN endoscopy (Pentax EC3490Fi; Pentax, Tokyo, Japan) with biopsies taken in the distal, mid, and proximal esophagus as well as from furrows or other endoscopic findings where visible. Esophageal endoscopic findings were photographed and catalogued on an electronic patient record (Endopro, Pentax, Japan) along with operator opinion on the suspicion or likelihood of EoE. Endoscopic reports and medical records were reviewed in order to obtain demographics and clinical details of the patients enrolled. 
- Table 3 Demographic characteristics of patients diagnosed with eosinophilic esophagitis.

\begin{tabular}{|c|c|}
\hline Characteristics & $\begin{array}{l}\text { EoE patients } \\
(n=45)\end{array}$ \\
\hline Male gender, n (\%) & $29(64.4)$ \\
\hline \multicolumn{2}{|l|}{ Age, y } \\
\hline - Median & 40 \\
\hline - Mean $\pm S D$ & $39.76 \pm 14.44$ \\
\hline - Range & $19-74$ \\
\hline \multicolumn{2}{|l|}{ Symptoms, n (\%) } \\
\hline - Progressive dysphagia & $6(13.3)$ \\
\hline - Intermittent dysphagia & $24(53.3)$ \\
\hline - Food bolus obstruction & $15(33.3)$ \\
\hline New diagnosis of EoE, n (\%) & $33(73.3 \%)$ \\
\hline Previous diagnosis of EoE, n (\%) & $12(26.7 \%)$ \\
\hline - Median duration of disease, $y$ & 3 \\
\hline \multicolumn{2}{|c|}{ - Treatment at time of endoscopy n, \% } \\
\hline - PPI & $5(41.7)$ \\
\hline - Oral steroid & 0 \\
\hline - $\mathrm{PPI}+$ oral steroid & $2(16.7)$ \\
\hline - None & $5(41.7)$ \\
\hline Allergy history, n (\%) & $3(6.7)$ \\
\hline Asthma history, n(\%) & $16(35.5)$ \\
\hline EoE, eosinophilic esophagitis & \\
\hline
\end{tabular}

\section{Endoscopic assessment}

All endoscopies were performed by a single endoscopist (M.I.) using HD-iSCAN virtual chromoendoscopy (Pentax EC-3490Fi; Pentax, Tokyo, Japan). iSCAN is a novel endoscopic technique developed by Pentax, Japan. It is a post-processing imaging technology that analyzes endoscopic images in real time and consists of 3 types of algorithms: surface enhancement (SE), contrast enhancement (CE) and tone enhancement (TE). Each of the algorithms can be selected by pressing a pre-assigned button on the hand piece of the endoscope [15]. Three iSCAN sets were used in sequences from set 1 to set 3 and pictures were taken for each single iSCAN set. All patients had the same technique applied systematically. Retrospective assessment (without knowledge of histology) of the iSCAN endoscopic pictures was performed by 2 endoscopists (MI and SG).

Presence of endoscopic key features described to define EoE [16] was evaluated in all patients including furrows, edema, rings or tracheal appearance, edema, white exudates and stricture or narrowing. No formal endoscopic scoring was done as this was a retrospective study. We took at least 2 biopsies in the distal and 2 biopsies in the mid and proximal esophagus and additional biopsies from the endoscopic features. Because we did not have a reference group we cannot draw conclusions about sampling bias and any change from targeting biopsies.

\section{Histological assessment}

Diagnosis of EoE requires quantification of esophageal eosinophilia. According to the consensus guidelines [4, 17], a diagnosis of EoE can be established if esophageal biopsies demonstrate $\geq 15$ eosinophils per high-power field (HFP) after an 8week trial of a proton-pump inhibitor (PPI) and if other causes of esophageal eosinophilia have been excluded. This was reported by the pathologist (XG) but not specifically for this retrospective study. The newly diagnosed patients, however, had clinical evaluation and also endoscopic evaluation after PPI, but our cohort only included their first endoscopy. This is a limitation. During endoscopy, esophageal biopsies from the proximal, mid and distal esophagus were obtained to maximize diagnostic sensitivity $[18,19]$. This was done systematically in all patients. Tissue samples were read and interpreted by a single pathologist who was blinded to the endoscopic findings (X. G.).

\section{Statistical analysis}

The parametric data are expressed as the mean and SD and categorical data are presented as percentages. Overall sensitivity, specificity, positive predictive value (PPV) and negative predic- 
- Table 3a Sensitivity and Specificity of endoscopic findings on WLE.

\begin{tabular}{|c|c|c|c|c|c|c|c|c|c|c|}
\hline \multirow[t]{3}{*}{ Study } & \multirow[t]{3}{*}{ Year } & \multirow[t]{3}{*}{$N$ (EoE) } & \multicolumn{8}{|c|}{ Endoscopic findings } \\
\hline & & & \multicolumn{2}{|l|}{ Rings } & \multicolumn{2}{|c|}{ Stricture } & \multicolumn{2}{|c|}{ Linear furrows } & \multicolumn{2}{|c|}{ White plaques } \\
\hline & & & Sens \% & Spec \% & Sens \% & Spec \% & Sens \% & Spec \% & Sens \% & Spec \% \\
\hline Ricker et al. [20] & 2011 & 28 & 46 & 97 & 0 & 97 & 43 & 96 & NA & NA \\
\hline Achem et al. [21] & 2011 & 24 & 54 & 78 & 4 & 100 & 21 & 99 & 25 & 88 \\
\hline Veerappan et al. [22] & 2009 & 25 & 52 & 94 & 28 & 91 & 48 & 95 & 20 & 98 \\
\hline Dellon et al. [23] & 2009 & 73 & 58 & 94 & 29 & 89 & 23 & 99 & 4 & 97 \\
\hline Prasad et al. [25] & 2007 & 33 & 30 & 92 & 12 & 98 & 21 & 97 & NA & NA \\
\hline
\end{tabular}

- Table 3b Positive and negative predictive values of endoscopic findings on WLE.

\begin{tabular}{|c|c|c|c|c|c|c|c|c|c|c|}
\hline \multirow[t]{3}{*}{ Study } & \multirow[t]{3}{*}{ Year } & \multirow[t]{3}{*}{$N$ (EoE) } & \multicolumn{8}{|c|}{ Endoscopic findings } \\
\hline & & & \multicolumn{2}{|c|}{ Rings } & \multicolumn{2}{|c|}{ Stricture } & \multicolumn{2}{|c|}{ Linear furrows } & \multicolumn{2}{|c|}{ White plaques } \\
\hline & & & PPV & NPV & PPV & NPV & PPV & NPV & PPV & NPV \\
\hline Ricker et al. [20] & 2011 & 28 & 81 & 86 & 0 & 76 & 75 & 85 & NA & NA \\
\hline Achem et al. [21] & 2011 & 24 & 29 & 91 & 100 & 86 & 71 & 88 & 25 & 88 \\
\hline Veerappan et al. [22] & 2009 & 25 & 38 & 97 & 18 & 95 & 39 & 96 & 36 & 95 \\
\hline Dellon et al. [23] & 2009 & 73 & 86 & 79 & 60 & 68 & 94 & 69 & 43 & 63 \\
\hline Prasad et al. [25] & 2007 & 33 & 40 & 88 & 50 & 86 & 54 & 88 & NA & NA \\
\hline
\end{tabular}

tive value (NPV) of endoscopic features as compared to positive histology was calculated. Histologic diagnosis was the reference gold standard. PPV and NPV of the combination of different endoscopic features were also calculated ( $\downarrow$ Table 1 ). The 2 endoscopists analyzed at least 4 high-quality images and anonymized HD-iSCAN images. Cohen's Kappa statistics were calculated to measure interobserver agreement, with 0.75 indicating good agreement, $0.4-0.75$ indicating fair to good agreement, and $<0.4$ indicating poor agreement. Statistical analyses were carried out using the SPSS statistical software package $v 19.1$ (IBM Corp., Armonk, New York, USA).

\section{Results}

\section{Demographic characteristics of patients}

One hundred and eighty-nine patients (53.4\% male, median age 55 , age range $18-85$ years) presented with dysphagia during the study period (August 2011 -July 2015). The cause of dysphagia of these patients is detailed in $>$ Table 2 . All patients had endoscopy and biopsies, and chest computed tomography scan and esophageal motility where clinically indicated. Fortyfive patients $(23.8 \%$, male $=29$, median age $40 y$, age range 19-74 years) had a histological diagnosis of EoE when eosinophil count per HPF was $>15$. Most of these patients were newly diagnosed with EoE (33 patients, $73.3 \%$ ), whereas 12 patients
(26.7\%) had a previous diagnosis of EoE. The patients had failed a proton pump inhibitor trial symptomatically. Twenty-four $(53.3 \%)$ patients presented with intermittent dysphagia, 6 (13.3\%) had progressive dysphagia and 15 (33.3\%) presented with acute food bolus obstruction. Ten (30.3\%) patients with a new diagnosis of EoE presented with a food bolus impaction. Demographic characteristics of the patients with EoE are summarized in $>$ Table 3.

\section{Endoscopic assessment by iSCAN}

By HD-iSCAN endoscopy 58 patients were suspected to have EoE, of whom 45 patients had a confirmed diagnosis by histology. Two patients had normal endoscopy but histology was diagnostic of EoE.

HD-iSCAN endoscopic characteristic features of EoE were linear furrows (91\%), edema $(77.8 \%)$, rings or tracheal appearance $(73.3 \%)$, whitish exudates $(26.6 \%)$ and narrowing or stricture $(5 \%)$.

The sensitivity and specificity of HD-iSCAN endoscopy were $97.62 \%$ (95\% Cl 87.43-99.94\%) and 89.58\% (95\% Cl 83.40$94.05 \%$ ), respectively. The positive predictive value (PPV) of HD-iSCAN endoscopy was $73 \%$ (95\% Cl 59,70-84.17\%) and the negative predictive value (NPV) was 99.23 (95\% Cl 95.7999.98\%). Accuracy of HD-iSCAN endoscopy was $92.47 \%$ (95\% $\mathrm{Cl} 87.67-95.56 \%)$. The interobserver agreement determined 


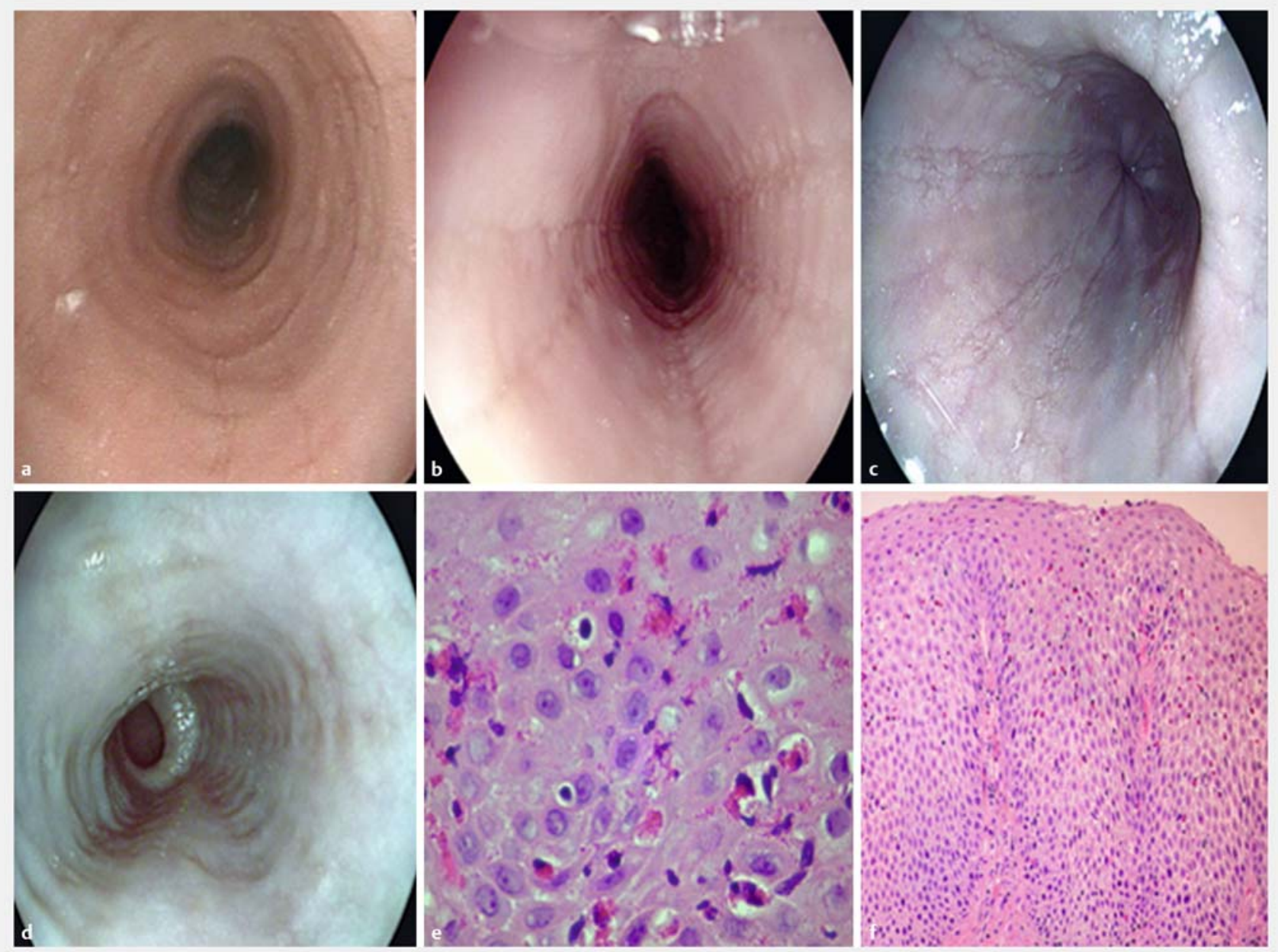

- Fig. 1 Endoscopic appearance of EoE. a White light endoscopy showed linear furrows with tracheal appearance. b, c, d High-definition virtual electronic chromoendoscopy in setting $2-3$ enhanced and better characterized the vertical furrows to aid the endoscopist to target biopsy.

by Kappa statistics for diagnosis of EoE was 0.81 (95\% Cl 0.70 $0.87)$.

\section{HD-iSCAN endoscopic features and histology}

Patients were diagnosed with EoE when median eosinophil count per HPF was $>15$. The intraepithelial eosinophil count had a mean of 62 with a standard deviation of \pm 47.62 . We did not analyze by location of biopsies.

Presence of linear furrows on HD-iSCAN endoscopy had a sensitivity of $91.11 \%(95 \% \mathrm{Cl} 78.78-97.52 \%)$, specificity of 93.75\% (95\% Cl 88.47-97.10\%), PPV 82\% (95\% Cl 68.56$97.12 \%)$, and NPV $97.12 \%$ (95\% CI 92.8-99.21\%). Presence of edema on HD-iSCAN endoscopy had a sensitivity of $77.78 \%$ (95 \% Cl 62.91-88.8\%), specificity 100\% (95\% Cl 97.47-100\%), PPV $100 \%$ (95\% Cl $90-100 \%)$ and NPV $93.51 \%(95 \% \mathrm{Cl}$ $88.38-96.84 \%)$. Presence of rings or tracheal appearance had a sensitivity of $73.33 \%$ (95\% Cl 58.06-85.40\%), specificity 93.06\% (95\% Cl 87.6-96.62\%), PPV 76.74\% (95\% Cl 61.37$88.24 \%$ ) and NPV $91.78 \%$ (95\% 86.08-95.68\%). White exudates had a sensitivity of $26.67 \%$ (95\% Cl $14.60-41.94 \%$ ), spe- cificity of $97.92 \%(95 \% \mathrm{Cl} 94.03-99.57 \%)$, PPV $80 \%(95 \% \mathrm{Cl}$ 51.91-95.67\%) and NPV 81.03\% (95\% Cl 74.41-86.57\%). Presence of narrowing or stricture had a sensitivity of $4.44 \%$ (95\% Cl 0.54-15.15\%), specificity $100 \%$ (95\% Cl 97.47-100 \%), PPV $100 \%$ (95\% Cl $15.81-100 \%)$, and NPV $77.01 \%(95 \% \mathrm{Cl}$ $70.30-82.83 \%)$.

Only 1 patient (2.22\%) with confirmed EoE by histology had the 5 endoscopic features (furrows, edema, rings or tracheal appearance, whitish exudates and narrowing or stricture), with a PPV of $100 \%$ (95\% Cl $2.5 \%-100 \%)$ and NPV $76.6 \%(95 \% \mathrm{Cl}$ $69.88-82.45 \%)$. Ten patients $(22.2 \%)$ had linear furrows, edema, rings or tracheal appearance and whitish exudates on HDiSCAN endoscopy, with a PPV $100 \%$ (95\% Cl 69.15-100\%) and NPV $80.45 \%$ (95\% Cl 73.87 - 85.99\%). Thirteen patients (29\%) presented with linear furrows, edema and rings or tracheal appearance on HD-iSCAN endoscopy, with a PPV $100 \%(95 \% \mathrm{Cl}$ $75.29-100 \%)$ and NPV $81.82 \%$ (95\% Cl 75.31-87.22\%). Six patients (13.3\%) had furrows and edema and 6 patients (13.3\%) had furrows and rings or tracheal appearance on HD 

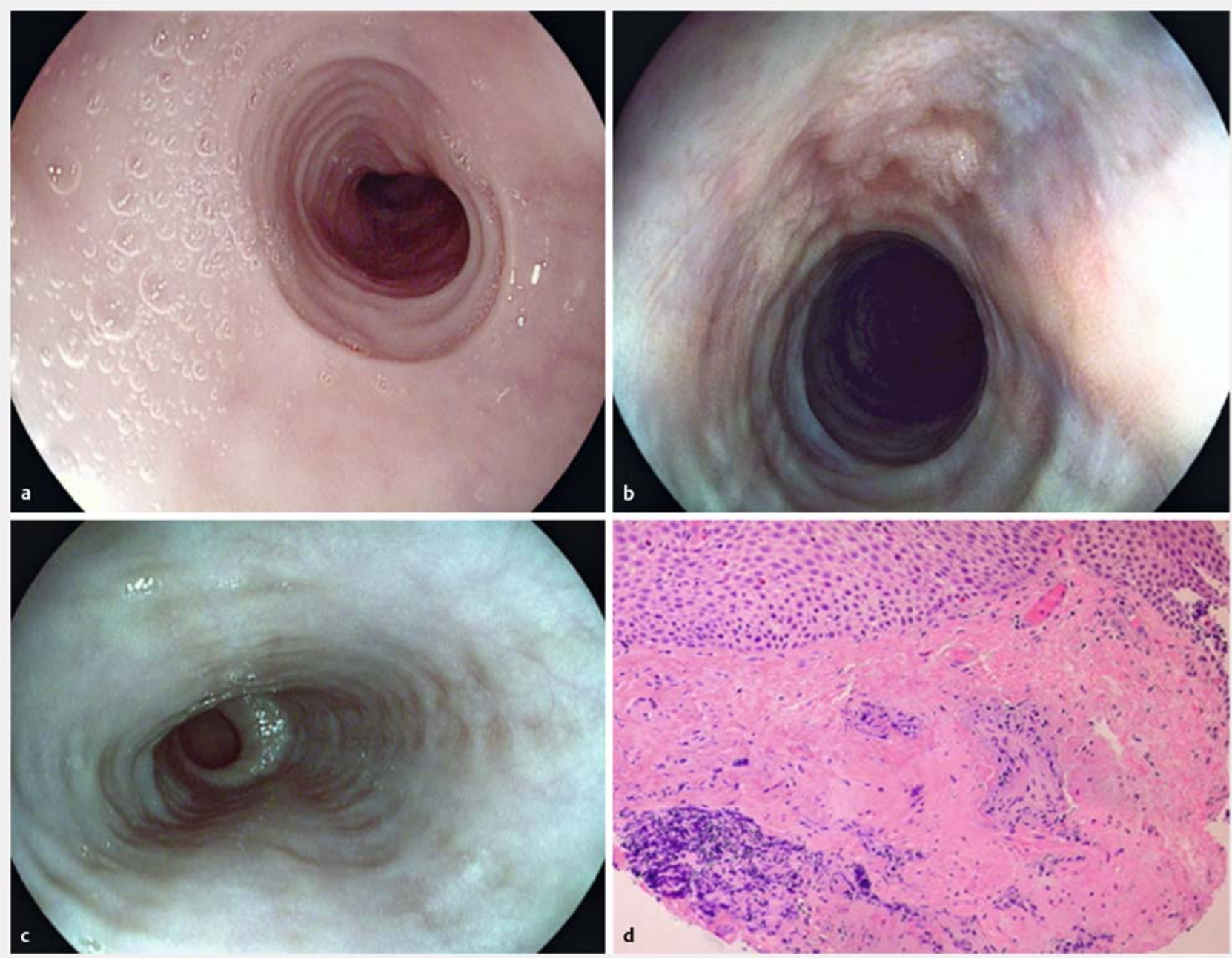

- Fig. 2 iSCAN appearance of EoE. a, b, c High-definition virtual chromoendosopcy in the setting of iSCAN 1, 2 and 3 showed rings, linear furrows and fibrotic changes to the esophagus. $\mathbf{d}$ H\&E revealed subepithelial fibrosis/hyalinization.

iSCAN endoscopy, with a PPV $100 \%(95 \% \mathrm{Cl} 54.07-100 \%)$ and NPV $78.69 \%(95 \% \mathrm{Cl} 72.04-84.38 \%)$ respectively (- Table 1 )

\section{Discussion}

In this retrospective observational study, we report our experience with using HD-iSCAN endoscopy in diagnosis of EoE, confirmed by histology. We report on individual endoscopy features (17) as well as overall endoscopic diagnosis of EoE using HD-iSCAN endoscopy. Linear furrows were the most common, while whitish exudates and strictures were least common.

Recently, many studies and meta-analysis have been done to study these endoscopic features with white light endoscopy and their reliability to aid the endoscopist in making EoE diagnosis. Unfortunately, the results have not shown uniformly good specificity and sensitivity of endoscopy alone without histology to predict diagnosis of EoE[10] ( $\triangleright$ Table 3a and $\triangleright$ Table 3b).

However, we found observationally that using HD-iSCAN electronic chromoendoscopy with high-definition endoscopy appeared to predict well a histological diagnosis of EoE ( $>$ Fig. 1, > Fig.2, and > Fig.3). In support, in our study we have showed very good sensitivity $(97.62 \%$ [95\% Cl $87.43-$ 99.94\%]), specificity (89.58\% [95\% Cl 83.40-94.05\%]), PPV (73\% [95\% Cl 59,70-84.17\%]), NPV (99.23 [95\% Cl 95.79$99.98 \%])$ and accuracy (92.47\% [95\% Cl 87.67-95.56\%]) of HD-iSCAN in diagnosis EoE. We did not directly compare it with white light endoscopy. However, all patients were assessed with iSCAN systematically using the 3 sets of electronic filters. We acknowledge that our patient population may be enriched by EoE patients and hence our PPV and NPV may be exaggerated.

The hypothesis in the study was that HD-iSCAN would highlight the endoscopic findings of EoE, and increase the diagnostic yield of EoE. To our knowledge, there are no published data on using HD-iSCAN in EoE. In this study, we did not have a control group of standard white light endoscopy with which to compare. Reported sensitivities, specificities, PPV and NVP of endoscopic findings on white light endoscopy in prior studies 

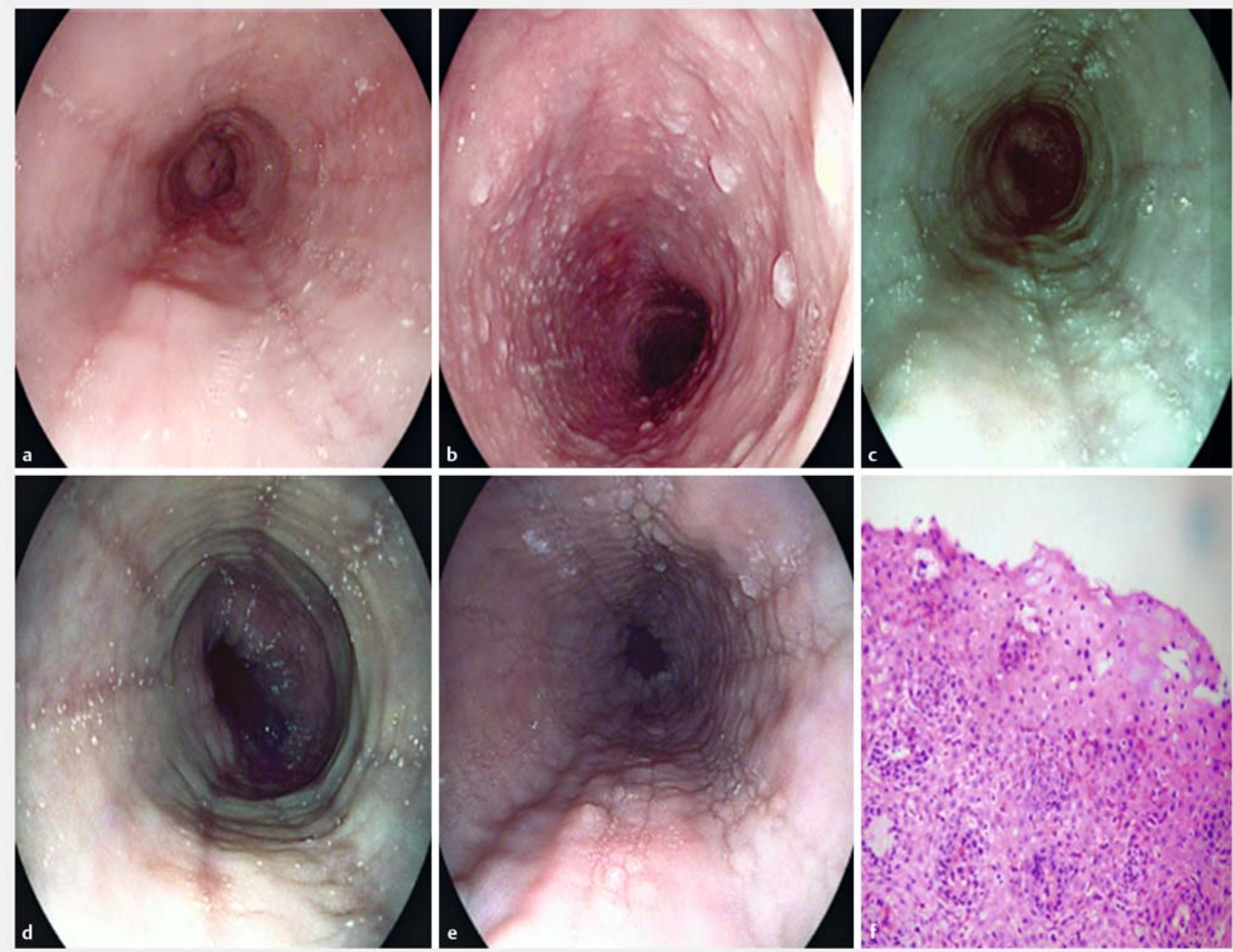

- Fig. 3 i SCAN a, b, c, d, e white light endoscopy with high-definition virtual chromoendoscopy in the different iSCAN settings 1, 2 and 3 characterized in detail whitish exudates and microabscess and linear furrows. $\mathbf{f} \mathrm{H} \& \mathrm{E}$ revealed a large number of intraepithelial eosinophilis as well as basal cell hyperplasia, spongiosis, and microabscesses.

range widely $[10,20-25]$ ( $>$ Table $3 \mathbf{a}$ and $\triangleright$ Table $3 \mathbf{b}$ ), depending on prevalence of EoE in the population studied.

Some published studies have used novel endoscopic techniques such as chromoendoscopy with indigo carmine dye spraying and narrow band Imaging (NBI) to enhance mucosal and vascular pattern and to increase detection and characterization of EoE endoscopic features. Peery et al. [14] have showed that NBI did not improve endoscopic recognition in adults and the intraobserver agreement was highly variable.

In contrast, in a study of erosive esophagitis, Lee and colleagues [26] found that NBI improved interobserver agreement, from an overall kappa of 0.45 to 0.62 . Lucendo et al [27] have used chromoendoscopy with Indigo carmine, which increased recognition and characterization of rings and furrows. Tanaka et al. [28] tried to identify additional endoscopic features such as capillary structure of the EoE patients using NBI Magnifying endoscopy. We also confirmed that edema, linear furrows and tracheal appearance were the most common endoscopic features by HD-iSCAN $[29,30]$.
The limited consensus on how best to characterize endoscopic findings in EoE and lack of standardized terminology and grading criteria and wide variability of interobserver agreement brought Hirano et al to develop and validate the eosinophilic esophagitis endoscopic references score (EREFS) [16]. This classification resulted in good interobserver agreement with $K$ of $0.46,043,054$ and 0.52 for exudates, rings, edema, furrows and stricture, respectively. Recently, van Rhijn et al [31] have further validated the EREFS score and tried to introduce it into clinical practice by every gastroenterologist. The interobserver $K$ value of agreement of each endoscopic finding improved $0.70,0.63,0.49$ and 0.54 for rings, exudates, furrows and stricture, respectively. However, there was still a wide range of intraobserver variability. We did not use the Hirano EREFS score as this is not validated for HD-iSCAN. As this is a retrospective study, no formal scoring was performed. We did not compare HD-iSCAN with white light endoscopy Recently, Dellon et al. have validated a set of clinical and endoscopic features to predict EoE with a high degree of accuracy and allow 
identification of those at very low risk of disease, reducing lowyield histological examinations for EoE [32].

The strength of agreement in our study between the 2 experts in iSCAN (M.I. and S. G.) for diagnosis of EoE was considered to be very good. The readers have performed more than 1,000 EGD procedures.

Novel advanced techniques have been increasingly adopted in endoscopic units and are slowly embraced by gastroenterologists in daily clinical practice. These techniques have been extensively investigated in the gastrointestinal tract, especially in the neoplasia field, and clearly have demonstrated better detection and characterization of lesions. These techniques might be aiding endoscopists in identifying an accurate set of endoscopic features and targeting smart biopsies, especially in mild and patchy EoE, which would be difficult to identify.

New and upcoming enhancements to endoscopic technique may increase accuracy of recognition of the entire spectrum of endoscopic findings in the EoE, and in the future, may reduce the wide interobserver and intraobserver variability between gastroenterologists.

Our exploratory study has some limitations. First, it was retrospective and performed at a single center. In this retrospective real-life study, it is inevitable that clinical presentation raised suspicion of EoE. We did not compare HD-iSCAN with white light endoscopy in this study as HD-iSCAN was used in all patients. Prevalence of EoE in patients presenting with dysphagia and/or food bolus impaction is likely to be high, resulting in overestimation of PPV or NPV in this report. Newly diagnosed patients had further evaluation after approximately 8 weeks of PPI therapy with endoscopic evaluation. However, only the first endoscopy was included in this study. Though retrospective, the same electronic chromoendoscopy technique was applied to all patients consecutively. In addition, the strength of the study is the fact that it is the first published study to assess EoE by using HD-iSCAN virtual chromoendoscopy. Second, the iSCAN procedures were performed by a single expert in novel enhanced endoscopic techniques. Although M. I. had performed the procedures, the second reader expert in iSCAN (S. G.) was blinded to ensure robustness of agreement. Another limitation was the fact that the second reader assessed the endoscopic findings using still images rather than videos sequences to reproduce live endoscopy. We plan to explore interobserver variability using HD-iSCAN video clips in a multicenter study with experts of HD-iSCAN and trainees in the near future.

\section{Conclusion}

In conclusion, high-definition iSCAN virtual chromoendoscopy promises to have potential value to improve the diagnostic accuracy in patients with EoE. However, additional questions still need to be answered in the future and studies are needed. Whether HD white light endoscopy alone maybe sufficient needs further clarification by prospective trials. These novel endoscopic techniques may help to identify a new pathognomonic esophageal vascular and mucosal pattern that can be used to identify EoE and differentiate it from other esophageal disorders, including reflux esophagitis. It would be very interesting to investigate this technique to assess response to therapy, especially with new emerging drugs, and to predict outcomes such as fibrosis and stricture. These novel endoscopic techniques are now available as standard on the new generation of endoscopes.

\section{Competing interests}

Dr.lacucci received an unrescrited grant from Pentax USA.

\section{References}

[1] Ferre-Ybarz L, Nevot Falco S, Plaza-Martin AM. Eosinophilic oesophagitis: clinical manifestations and treatment options. The role of the allergologist. Allergol et Immunopathol 2008; 36: 358-365

[2] Sgouros SN, Bergele C, Mantides A. Eosinophilic esophagitis in adults: a systematic review. Eur J Gastroenterol Hepatol 2006; 18: 211-217

[3] Dellon ES, Jensen ET, Martin CF et al. Prevalence of eosinophilic esophagitis in the United States. Clin Gastroenterol Hepatol 2014; 12: 589-596

[4] Liacouras CA, Furuta GT, Hirano I et al. Eosinophilic esophagitis: updated consensus recommendations for children and adults. J Allergy Clin Immunol 2011; 128: 3-20

[5] Landres RT, Kuster GG, Strum WB. Eosinophilic esophagitis in a patient with vigorous achalasia. Gastroenterology 1978; 74: 1298 1301

[6] Hruz P, Straumann A, Bussmann C et al. Escalating incidence of eosinophilic esophagitis: a 20-year prospective, population-based study in Olten County, Switzerland. J Allergy Clin Immunol 2011; 128: $1349-1350$

[7] Ronkainen J, Talley NJ, Aro P et al. Prevalence of oesophageal eosinophils and eosinophilic oesophagitis in adults: the population-based Kalixanda study. Gut 2007; 56: 615-620

[8] Straumann A, Simon HU. Eosinophilic esophagitis: escalating epidemiology? J Allergy Clin Immunol 2005; 115: 418 -419

[9] Saffari H, Peterson KA, Fang JC et al. Patchy eosinophil distributions in an esophagectomy specimen from a patient with eosinophilic esophagitis: Implications for endoscopic biopsy. J Allergy Clin Immunol 2012; 130: $798-800$

[10] Kim HP, Vance RB, Shaheen NJ et al. The prevalence and diagnostic utility of endoscopic features of eosinophilic esophagitis: a meta-analysis. Clin Gastroenterol and Hepatol 2012; 10: 988-996

[11] Hori K, Watari J, Fukui H et al. Do endoscopic features suggesting eosinophilic esophagitis represent histological eosinophilia? Dig Endosc 2014; 26: $156-163$

[12] Salek J, Clayton F, Vinson L et al. Endoscopic appearance and location dictate diagnostic yield of biopsies in eosinophilic oesophagitis. Aliment Pharmacol Ther 2015; 41: 1288-1295

[13] Tanaka K, Rubio CA, Dlugosz A et al. Narrow-band imaging magnifying endoscopy in adult patients with eosinophilic esophagitis/esophageal eosinophilia and lymphocytic esophagitis. Gastrointest Endosc 2013; 78: 659-664

[14] Peery AF, Cao H, Dominik R et al. Variable reliability of endoscopic findings with white-light and narrow-band imaging for patients with suspected eosinophilic esophagitis. Clinic Gastroenterol Hepatol 2011; 9: 475-480

[15] Kodashima S, Fujishiro M. Novel image-enhanced endoscopy with i-scan technology. World J of Gastroenterol 2010; 16: 1043 - 1049 
[16] Hirano I, Moy N, Heckman MG et al. Endoscopic assessment of the oesophageal features of eosinophilic oesophagitis: validation of a novel classification and grading system. Gut 2013; 62: 489-495

[17] Dellon ES, Gonsalves N, Hirano I et al. ACG clinical guideline: Evidenced based approach to the diagnosis and management of esophageal eosinophilia and eosinophilic esophagitis (EoE). Am J Gastroenterol 2013; 108: 679-692

[18] Dellon ES, Speck O, Woodward K et al. Distribution and variability of esophageal eosinophilia in patients undergoing upper endoscopy. Mod Pathol 2015; 28: $383-390$

[19] Gonsalves N, Policarpio-Nicolas M, Zhang Q et al. Histopathologic variability and endoscopic correlates in adults with eosinophilic esophagitis. Gastrointest Endosc 2006; 64: 313-319

[20] Ricker J, McNear S, Cassidy T et al. Routine screening for eosinophilic esophagitis in patients presenting with dysphagia. Therap Adv Gastroenterol 2011; 4: $27-35$

[21] Achem SR, Almansa C, Krishna M et al. Oesophageal eosinophilic infiltration in patients with noncardiac chest pain. Aliment Pharmacol \& Ther 2011; 33: $1194-1201$

[22] Veerappan GR, Perry JL, Duncan T] et al. Prevalence of eosinophilic esophagitis in an adult population undergoing upper endoscopy: a prospective study. Clinic Gastroenterol Hepatol 2009; 7: 420-4266

[23] Dellon ES, Gibbs WB, Fritchie KJ et al. Clinical, endoscopic, and histologic findings distinguish eosinophilic esophagitis from gastroesophageal reflux disease. Clinic Gastroenterol Hepatol 2009; 7: $1305-$ 1313 ; quiz 261

[24] Lee GS, Craig PI, Freiman JS et al. Intermittent dysphagia for solids associated with a multiringed esophagus: clinical features and response to dilatation. Dysphagia 2007; 22 : $55-62$

[25] Prasad GA, Talley NJ, Romero Y et al. Prevalence and predictive factors of eosinophilic esophagitis in patients presenting with dysphagia: a prospective study. American J Gastroenterol 2007; 102: 2627 - 2632
[26] Lee YC, Lin JT, Chiu HM et al. Intraobserver and interobserver consistency for grading esophagitis with narrow-band imaging. Gastrointest Endosc 2007; 66: 230 - 236

[27] Lucendo AJ, De Rezende LC, González-Castillo S et al. S1874 Chromoendoscopy with Indigo-Carmine Improves the Recognition of Endoscopic Mucosal Findings in Adult Eosinophilic Esophagitis. Gastroenterology 2009; 136: A-282

[28] Tanaka K, Rubio CA, Dlugosz A et al. Narrow-band imaging magnifying endoscopy in adult patients with eosinophilic esophagitis/esophageal eosinophilia and lymphocytic esophagitis. Gastrointest Endosc 2013; 78: 659-664

[29] Eustace G, Gui X, lacucci M. Recent advances in the recognition and management of eosinophilic esophagitis. Can J Gastroenterol Hepatol 2015; 29: $237-240$

[30] Iacucci M, Gasia MF, Ghosh S et al. To Improve the Evaluation of Eosinophilic Esophagitis by Using High-Definition iSCAN Virtual Chromoendoscopy in Combination With a Refined Histology Scoring System. Gastroenterology 2015; 148: S-826

[31] van Rhijn BD, Warners MJ, Curvers WL et al. Evaluating the endoscopic reference score for eosinophilic esophagitis: moderate to substantial intra- and interobserver reliability. Endoscopy 2014; 46: 1049-1055

[32] Dellon ES, Rusin S, Gebhart JH et al. A Clinical Prediction Tool Identifies Cases of Eosinophilic Esophagitis Without Endoscopic Biopsy: A Prospective Study. American J Gastroenterol 2015; 110: 1347-1354

[33] Abu Dayyeh BK, Thosani N. ASGE Technology Committee. et al. ASGE Technology Committee systematic review and meta-analysis assessing the ASGE PIVI thresholds for adopting real-time endoscopic assessment of the histology of diminutive colorectal polyps. Gastrointest Endosc 2015; 81: 502.e1 - 502e16 